\title{
FUNÇÕES DE PEDOTRANSFERÊ NCIA PARA PREDIÇÃO DA UMIDADE RETIDA A POTENCIAIS ESPECÍFICOS EM SOLOS DO ESTADO DE PERNAMBUCO(1)
}

\author{
L. B. OLIVEIRA(2), M. R. RIBEIRO(3), P. K. T. J ACOMINE(3), \\ J.J.V.RODRIGUES ${ }^{(3)} \&$ F. A. MARQUES $S^{(4)}$
}

\begin{abstract}
RESUMO
Funções de pedotransferência são equações usadas para estimar características edáficas de difícil determinação a partir de outras mais facilmente obtidas. Apesar do bom número de equações disponíveis para estimativa da umidade retida a potenciais matriciais específicos, elas não devem ser usadas indiscriminadamente, pois, em sua maioria, foram desenvolvidas com solos de clima temperado e a partir de dados gerados por métodos diversos dos em uso nos laboratórios brasi lei ros. O presente trabal ho teve por objetivos: (a) elaborar funções de pedotransferência para estimar o conteúdo de água nos potenciais de -33 e -1.500 kPa e a água disponível, a partir de dados granulométricos e de densidade do solo, para solos do estado de Pernambuco e (b) comparar a eficiência de predição das equações propostas em relação a equações similares, disponíveis na literatura. No desenvolvimento das equações, foi uti lizada uma base de dados composta por 98 perfis de solos e 467 horizontes. Os perfis foram agrupados, de acordo com Sistema Brasileiro de Classificação de Solos, em 27 classes de terceiro nível categórico (grande grupo). As equações desenvolvidas apresentaram bons coeficientes de determinação e baixo erro de predição. A sistematização dos dados por atividade da fração argila ou grau aproximado de desenvolvimento ou classe textural não produziu melhorias na capacidade preditiva das pedofunções. As equações propostas em outros trabal hos apresentaram elevado erro de predição, o que restringe a sua utilização para solos do estado de Pernambuco.
\end{abstract}

Termos de indexação: pedofunções, capacidade de campo, ponto de murcha permanente, água disponível, conteúdo de água.

\footnotetext{
(1) Trabalho a ser apresentado no XXVIII Congresso Brasileiro de Ciência do Solo. Recebido para publicação em junho de 2001 e aprovado em janeiro de 2002.

(2) Mestrando do Programa de Pós-Graduação em Agronomia - Ciência do Solo, Universidade Federal Rural de Pernambuco UFRPE. Rua Prof. Chaves Batista, 159, CDU, CEP 50740-030 Recife (PE). E-mail: Ibdeoliveira@yahoo.com.br

(3) Professor do Departamento de Agronomia, UFRPE. Bolsista do CNPq. E-mail: rosas@truenet.com.br

(4) Discente do curso de Engenharia Agronômica, UFRPE.
} 


\begin{abstract}
SUMMARY: PEDOTRANSFER FUNCTIONS FOR THE PREDICTION OF MOISTURE RETENTION AND SPECIFIC POTENTIALS IN SOILS OF PERNAMBUCO STATE (BRAZIL)
\end{abstract}

\begin{abstract}
Pedotransfer functions are equations used to estimate soil properties of difficult determination, based on other, more easily obtained soil properties. In spite of the considerablenumber of equations available to predict moisture retention to specific matrix potentials, these should not be used indiscriminatley,since most of them were devel oped in temperate climate soils, using data obtained by method that differ from the ones used in Brazilian laboratories. The objectives of this study were: (a) to develop pedotransference functions to estimate water retention at potentials between -33 and $-1,500 \mathrm{kPa}$ and water availability, using particl esizedistribution and gl obal density data from soils of Pernambuco State, and (b) to comparetheprediction efficiency of thenew equations with similar equations available in literature. A database of 467 soil horizons from 98 soil profiles was used to develop the equations. The profiles were grouped, according to the Brazilian Soil Classificati on System, in 27 third category level classes (great group) Theobtai ned equations showed worth whiledetermination coefficients and low prediction standard error. Data grouping according to clay fraction, approximated devel opment rateor textural dass, did not i mprove theprediction capacity of the pedofunctions. Theequations proposed in other works presented high prediction errors and are not recommended for soils of Pernambuco State.
\end{abstract}

Index terms: Pedofunctions, field capacity, permanent wilting point, water content.

\section{NTRODUÇÃO}

A umidade retida pelo solo em potenciais matriciais específicos é largamente utilizada como critério no dimensionamento de projetos de irrigação e em outras áreas da agronomia, que incluem estudos de: disponibilidade de água às plantas, infiltração, drenagem, condutividade hidráulica, estresse hídrico e movimento de solutos no solo (Saxton et al., 1986; Kern, 1995). Os três principais critérios utilizados são conhecidos como capacidade de campo (CC), ponto de murcha permanente (PMP) e água disponível (AD). A capacidade de campo corresponde ao limite superior da faixa de disponibilidade de água às plantas, e o conteúdo de água correspondenteé, comumente, determinado nos potenciais matriciais de-10 kPa, para sol os detextura arenosa, ou de-33 kPa, para solos de textura média a argilosa (EMBRAPA, 1995). O limite inferior da faixa de disponibilidade eqüivaleaoPMP ea umidade correspondente é determinada submetendo-se amostras de soloà tensão de $1.500 \mathrm{kPa}$. A diferença entre os teores de água retidos na CC e no PMP é tida como água disponível. Essas definições, embora prescindam deum consistente embasamentoteórico, como advogaram Reichardt (1988) e Lier (2000), são, inegavelmente, úteis na avaliação da aptidão agrícol a das terras destinadas à agricul tura irrigada ou de sequeiro.

A determinação destas propriedades no campo é laboriosa, demorada e de custo el evado (Muelem (1986) e Bouma (1983) citados por Lin et al., 1999). No laboratório, persistem problemas de custo, morosidade e inexatidão. Particularmente, no Nordeste brasileiro, destaca-se o problema da escassez de laboratórios com instrumental adequado para tais determinações.

Partindo da hipótese de que há estreitas relações entre as características de retenção de umidade e outras características edáficas mais facilmente mensuráveis, pesquisadores como Salter \& Williams (1965), Salter et al. (1966), Petersen et al . (1968), Ahuja et al . (1985), Saxton et al . (1986), Arruda et al (1987), Meng et al. (1987), Rawls et al. (1991), Kern (1995), Berg et al. (1997), dentre outros, utilizaram-se de princípios galtonianos para elaborar equações com vistas em estimar os parâmetros supramencionados. Bouma (1989), citado por Pachepsky \& Rawls (1999), introduziu o termo Funções de Pedotransferência (FPT), para referir-se às equações que relacionam características de retenção de umidade ou condutividade hidráulica com outras características mais facilmente obtidas. Atualmente, este termo é empregado num sentido mais abrangente, para designar as equações que estimam características edáficas de difícil obtenção a partir de outras mais facilmente obtidas, incluindo, até mesmo, características morfológicas, como fizeram Lin et al. (1999).

Atualmente, número considerável de trabalhos propõem equações para predição do conteúdo de água retida pelo sol o nos potenciais equivalentes à CC, PMP e a AD. No entanto, estas equações não devem ser usadas indiscriminadamente, pois, em sua maioria, foram desenvolvidas com solos de clima temperado e seu uso imprescinde de calibrações locais. As funções de pedotransferência tendem a 
ser tão mais acuradas quanto mais homogêneos forem os sol os que compõem a base de dados e quão mais próximos destes estiverem os que terão seus dados estimados. Outro problema refere-se a diferenças nos métodos analíticos empregados para obtenção das variáveis dependentes eindependentes.

Por estas razões, foi desenvolvido o presente trabalho que objetivou: (a) elaborar funções de pedotransferência para estimar o conteúdo de água nos potenciais de-33 e-1.500 kPa ea água disponível entre estes potenciais a partir de dados granulométricos e de densidade do solo para solos do estado de Pernambuco e (b) comparar a eficiência de predição das equações propostas com equações similares, disponíveis na literatura, na estimativa destas propriedades.

\section{MATERIAL E MÉTODOS}

As funções de pedotransferência foram desenvolvidas a partir de dados de 98 perfis de solos, num total de 467 horizontes. Foram incluídos 32 perfis da coleção de Solos de Referência do Estado de Pernambuco, dados ainda não publicados de trabal hos realizados pel os autores e dados publicados por outros autores (Quadro 1).

A classificação dos sol os foi atualizada de acordo com o Sistema Brasileiro de Classificação de Sol os (EMBRAPA, 1999), e os 98 perfis selecionados ficaram agrupados em 27 classes taxonômicas de terceironível categórico (grandes grupos) (Quadro 2).

A umidade retida nos potenciais matriciais de -33 e -1.500 kPa foi obtida a partir de amostras deformadas de solo, coletadas por horizonte, no extrator de Richards, de acordo com métodos propostos pela EMBRAPA (1979). A água disponível

Quadro 1. Origem dos dados que compuseram a base para elaboração das funções de pedotransferência

\begin{tabular}{lc}
\hline \multicolumn{1}{c}{ Fonte } & No de Perfis \\
\hline Coleção Solos de Referência do Estado de & 32 \\
Pernambuco & \\
Trabalhos não publicados & 6 \\
Alves (1994) & 8 \\
CODE VASF (1998) & 5 \\
Costa (1988) & 29 \\
Dantas (1996) & 4 \\
Gusmão (1993) & 1 \\
Luz (1989) & 3 \\
Oliveira Neto (1992) & 3 \\
Parahyba (1993) & 3 \\
Souto Maior (1996) & 4 \\
\hline
\end{tabular}

Quadro 2. Classificação dos solos e número de perfis correspondentes utilizados na elaboração das funções de pedotransferência

\begin{tabular}{lc}
\hline \multicolumn{1}{c}{ Classe de solo } & No de Perfis \\
\hline Argissolo Amarelo eutrófico & 9 \\
Argissolo Amarelo distrófico & 29 \\
Argissolo Vermelho-Amarelo eutrófico & 3 \\
Argissolo Vermelho-Amarelo distrófico & 5 \\
Argissolo Vermelho eutrófico & 3 \\
Argissolo Vermelho distrófico & 2 \\
Cambissolo Háplico tb eutrófico & 1 \\
Cambissolo Háplico tb distrófico & 1 \\
Chernossolo Argilúvico órtico & 1 \\
Espodossolo Cárbico órtico & 1 \\
Espodossolo Ferrocárbico órtico & 1 \\
Latossolo Amarelo distrófico & 7 \\
Latossolo Vermel ho-Amarelo distrófico & 1 \\
Luvissolo Crômico órtico & 4 \\
Neossolo Flúvico sálico & 1 \\
Neossolo Flúvico sódico & 3 \\
Neossolo Flúvico ta eutrófico & 1 \\
Neossolo Litólico eutrófico & 1 \\
Neossolo Quartzarênico órtico & 3 \\
Neossolo Regolítico distrófico & 4 \\
Nitossolo Vermelho distroférrico & 1 \\
Planossolo Háplico eutrófico & 10 \\
Planossolo Nátrico órtico & 1 \\
Planossolo Nátrico sálico & 2 \\
Plintossolo Argilúvico eutrófico & 1 \\
Plintossolo Argilúvico distrófico & 1 \\
Vertissolo Cromado órtico & 1 \\
&
\end{tabular}

foi obtida pela diferença entre a umidade retida a -33 e-1.500 kPa. O uso de amostras deformadas para elaboração das pedofunções parecenão ser a situação ideal, pois a retenção de umidade pelo solo, especialmente na CC, é também influenciada pela estrutura, ealterações na mesma podem limitar, em muito, a exatidão dos resultados obtidos, como salientado por Vereecken et al. (1989). No entanto, alguns trabalhos, como o realizado por Medina \& Oliveira J r. (1987), mostraram mel hores correlações entre dados obtidos com amostras deformadas do que os obtidos com amostras indeformadas, em relação aos obtidos pela determinação da capacidade de campo in situ.

Para o estado de Pernambuco, atualmente, são raros os dados disponíveis de retenção de umidade obtidos a partir de amostras indeformadas de solos. Por tal razão, mesmo sabendo das possíveis limitações ao alcance do trabalho, optou-se pela elaboração das pedofunções a partir de amostras deformadas, por serem estes os dados ora disponíveis. Futuramente, quando houver disponibilidade de dados gerados a partir de amostras indeformadas, as pedofunções aqui sugeridas devem ser substituídas por outras que, espera-se, melhor representem a condição de campo. 
Os teores de argila foram obtidos pel o método do densímetro, utilizando-se hexametafosfato de sódio $0,350 \mathrm{~mol} \mathrm{~L}^{-1}$. Os teores de areia foram obtidos por peneiramentoúmi do eos de silte pela diferença entre a massa da amostra seca eos teores de areia +argila, de acordo com EMBRAPA (1979). A densidade do solo foi determinada em amostras indeformadas, pelo método do cilindro volumétrico $\left(250 \mathrm{~cm}^{-3}\right)$ ou do torrão parafinado, conforme preconizado pela EMBRAPA (1979).

Na tentativa de melhorar a capacidade preditiva das pedofunções, além da utilização dos dados agrupados num único conjunto, procedeu-se à separação dos dados em categorias, formando subconjuntos mais homogêneos. Os subconjuntos incluíram: atividade de argila (alta ou baixa de acordo com E MBRAPA, 1999), grau aproximado de desenvol vimento pedogenético (pouco desenvol vido, parcialmente desenvolvido e desenvolvido a muito desenvol vido) edassetextural (arenosa, média, siltosa, argilosa e muito argilosa), conforme EMBRAPA (1999). A sistematização das dasses desolos deacordo com o grau aproximado de desenvol vimento pedogené tico seguiu a divisão apresentada no quadro 3.

Para avaliar as funções de pedotransferência, utilizou-se outra base de dados, composta por 22 perfis e 92 horizontes retirados do trabalho de Ribeiro (1982).

Na comparação da eficiência de predição das pedofunções obtidas, foram adotados, como critérios, o coeficiente de determinação e o erro-padrão da estimativa (EPE).

As equações disponíveis na literatura, escol hidas para comparação, foram selecionadas, seguindo-se os seguintes critérios: (a) envolver apenas propriedades texturais e, ou, densidade do solo e (b) ter sido desenvolvida a partir de amostras deformadas.

A avaliação da eficiência preditiva das funções propostas por outros autores baseou-se na raiz da média do quadrado do er ro da estimativa (MRQEE), no coeficiente de correlação, na média relativa do erro de estimativa (MREE) e na análise gráfica. A
Quadro 3. Escala evolutiva adotada para agrupar as classes de solo

\begin{tabular}{|c|c|}
\hline $\begin{array}{l}\text { Grau aproximado } \\
\text { de desenvolvimento }\end{array}$ & $\begin{array}{c}\text { Classe de solo } \\
\text { (E MBRAPA, 1999) }\end{array}$ \\
\hline Solos pouco desenvolvidos & Neossolos \\
\hline & $\begin{array}{l}\text { Cambissolos } \\
\text { Chernossolos }\end{array}$ \\
\hline Solos parcialmente desenvolvidos & $\begin{array}{l}\text { Luvissolos } \\
\text { Planossolos } \\
\text { Vertissolos }\end{array}$ \\
\hline $\begin{array}{l}\text { Solos desenvolvidos a muito } \\
\text { desenvolvidos }\end{array}$ & $\begin{array}{l}\text { Argissolos } \\
\text { Espodossolos } \\
\text { Latossolos } \\
\text { Nitossolos } \\
\text { Plintossolos }\end{array}$ \\
\hline
\end{tabular}

MREE foi calculada a partir da equação propostas por Ahuja et al. (1985) eK ern (1995), mas os valores foram expressos em percentagem para facilitar as comparações e diminuir o efeito conservativo deste indicador para baixos conteúdos de água.

As equações foram obti das por meio do programa SYSTAT (SYSTAT, 1993), pelo método Stepwise a 1\%.

\section{RESULTADOS E DISCUSSÃO}

\section{Desenvolvimento e validação das pedofunções}

A amplitude de variação para as diferentes propriedades utilizadas é apresentada no quadro 4. A textura dos sol os utilizados variou dearenosa (com teores de areia de até $950 \mathrm{~g} \mathrm{~kg}^{-1}$ de solo) a muito argil osa (teores de argila de $830 \mathrm{~g} \mathrm{~kg}^{-1}$ de solo). Os maiores teores de areia foram obtidos para os Neossolos Quartzarênicos órticos, enquanto os teores

Quadro 4. Valores míni mos, máxi mos, médios e desvio-padrão para as diferentes propriedades utilizadas na elaboração das pedofunções

\begin{tabular}{|c|c|c|c|c|c|c|c|}
\hline \multirow{2}{*}{ Propriedades } & \multirow{2}{*}{ Areia } & \multirow{2}{*}{ Silte } & \multirow{2}{*}{ Argila } & \multirow{2}{*}{ Ds $\mathbf{s}^{(1)}$} & \multicolumn{3}{|c|}{ Umidade } \\
\hline & & & & & $-33 k P a$ & $-1.500 \mathrm{kPa}$ & $A^{(2)}$ \\
\hline & 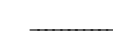 & $-\mathrm{g} \mathrm{kg}^{-1}$ & - & $\mathrm{t} \mathrm{m}^{-3}$ & 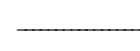 & $-\mathrm{kg} \mathrm{kg}^{-1}$ & - \\
\hline $\begin{array}{l}\text { Mínimo } \\
\text { Máximo }\end{array}$ & $\begin{array}{r}50 \\
950\end{array}$ & $\begin{array}{r}10 \\
457\end{array}$ & $\begin{array}{r}20 \\
830\end{array}$ & $\begin{array}{l}1,02 \\
2,06\end{array}$ & $\begin{array}{l}0,0170 \\
0,4630\end{array}$ & $\begin{array}{l}0,0080 \\
0,3340\end{array}$ & $\begin{array}{l}0,0030 \\
0,3560\end{array}$ \\
\hline Média & 550 & 136 & 313 & 1,50 & 0,1715 & 0,1022 & 0,0650 \\
\hline Desvio-padrão & 201 & 85 & 179 & 0,21 & 0,0838 & 0,0639 & 0,034 \\
\hline
\end{tabular}

${ }^{(1)}$ Densidade do solo. ${ }^{(2)}$ Água disponível. 
mais el evados de argila foram obtidos para o Nitossolo Vermel ho distroférrico. Os valores de densidade do sol ovariaram de 1,02 a 2,06 $\mathrm{t} \mathrm{m}^{-3}$. Este elevado valor de densidade do solo foi obtido por Souto Maior (1996), para um horizonte $\mathrm{Btf}_{3}$ de um perfil de Argissolo Amarelo eutrófico plíntico, de Santa Maria da Boa Vista (PE). O conteúdo deágua retido nos potenciais de-33 e-1.500 kPa e o deágua disponível variou de 0,0170 a 0,4630; 0,0080 a 0,3340; 0,0030 a $0,3560 \mathrm{~kg} \mathrm{~kg}^{-1}$, respectivamente.

No quadro 5, são apresentadas as equações de regressão para a estimativa do conteúdo de água nos potenciais de -33 e-1.500 kPa, bem como para a água disponível. Os coeficientes de determinação das equações foram superiores aos da maioria dos trabal hos similares consultados (Arruda et al., 1987; Meng et al., 1987; Bell \& van Keulen, 1995; Masutti, 1997), principalmente para o conteúdo de água disponível.

O agrupamento dos dados em subconjuntos baseado na classe textural ou na atividade da fração argila ou no grau aproximado de desenvol vimento, de maneira geral, não produziu melhorias consideráveis na capacidade preditiva das

\section{Quadro 5. Equações para estimativa da umidade de solos pernambucanos $\left(\mathrm{kg} \mathrm{kg}^{-1}\right)$ e respectivos} coeficientes de determi nação $\left(R^{2}\right)$ e erro-padrão da esti mativa (E PE)

\begin{tabular}{|c|c|c|c|}
\hline Umidade(1) & E quação(2) & $\mathbf{R}^{2(3)}$ & EPE \\
\hline \multicolumn{4}{|c|}{ Conjunto único de dados } \\
\hline$\hat{U}_{-33 \mathrm{kPa}}$ & $=0,000333$ Silte $+0,000387$ Argila & $0,960 * *$ & 0,0384 \\
\hline$\hat{U}_{-1.500 \mathrm{kPa}}$ & $=0,000038$ Areia $+0,000153$ Silte $+0,000341$ Argila $-0,030861 \mathrm{Ds}$ & $0,955^{* *}$ & 0,0257 \\
\hline$\hat{U}_{33-1.500 \mathrm{kPa}}$ & $=-0,000021$ Areia $+0,000203$ Silte $+0,000054$ Argila $+0,021656 \mathrm{Ds}$ & $0,890 * *$ & 0,0244 \\
\hline \multicolumn{4}{|c|}{ Separação por classe textural } \\
\hline \multicolumn{4}{|c|}{ Textura média } \\
\hline$\hat{U}_{-33 \mathrm{kPa}}$ & $=0,000341$ Silte $+0,000374$ Argila & $0,945^{* *}$ & 0,0356 \\
\hline$\hat{U}_{-1.500 \mathrm{kPa}}$ & $=-0,000056$ Areia $+0,000158$ Silte $+0,000067$ Argila $+0,038680 \mathrm{Ds}$ & $0,922 * *$ & 0,0207 \\
\hline$\hat{U}_{33-1.500 \mathrm{kPa}}$ & $\begin{aligned}= & -0,000178 \mathrm{Areia}+0,000286 \mathrm{Argila}+0,103088 \mathrm{Ds} \\
& \text { Textura argilosa }\end{aligned}$ & $0,938 * *$ & 0,0324 \\
\hline$\hat{\mathrm{U}}-33 \mathrm{kPa}$ & $=0,000079$ Areia $+, 0,000444$ Silte $+0,000484$ Argila $-0,069234 \mathrm{Ds}$ & $0,964 * *$ & 0,0429 \\
\hline$\hat{\mathrm{U}}-1.500 \mathrm{kPa}$ & $=0,000032$ Areia $+0,000223$ Silte $+0,00062$ Argila & $0,856 * *$ & 0,0311 \\
\hline$\hat{U}_{33-1.500 \mathrm{kPa}}$ & $\begin{array}{l}=0,000104 \text { Areia }+0,000150 \text { Silte }+0,000372 \text { Argila }+0,039788 \mathrm{Ds} \\
\text { Textura muito argilosa }\end{array}$ & $0,968^{* *}$ & 0,0374 \\
\hline$\hat{U}-33 \mathrm{kPa}$ & $=-0,000328$ Areia $+0,00571$ Argila & $0,985^{* *}$ & 0,0383 \\
\hline$\hat{U}_{-1.500 \mathrm{kPa}}$ & $=0,000282$ Silte $+0,000487$ Argila $-0,101537 \mathrm{Ds}$ & $0,987^{* *} *$ & 0,0265 \\
\hline$\hat{U}_{33-1.500 \mathrm{kPa}}$ & $=-0,000124$ Areia $+0,000107$ Silte $+0,000088$ Argila $+0,032813 \mathrm{Ds}$ & $0,970 * *$ & 0,0216 \\
\hline \multicolumn{4}{|c|}{ Separação por atividade de argila } \\
\hline & Argila de atividade alta & & \\
\hline$\hat{U}_{-33 \mathrm{kPa}}$ & $=-0,000050$ Areia $+0,000190$ Silte $+0,000326$ Argila $+0,0473371 \mathrm{Ds}$ & $0,967 * *$ & 0,3530 \\
\hline$\hat{U}-1.500 \mathrm{kPa}$ & $=0,000087$ Silte $+0,000285$ Argila & $0,952 * *$ & 0,0237 \\
\hline$\hat{\mathrm{U}}_{33-1.500 \mathrm{kPa}}$ & $\begin{aligned}= & -0,000035 \mathrm{Areia}+0,000104 \mathrm{Silte}+0,000048 \mathrm{Argila}+0,041646 \mathrm{Ds} \\
& \text { Argila de atividade baixa }\end{aligned}$ & $0,943 * *$ & 0,0214 \\
\hline$\hat{U}_{-33 \mathrm{kPa}}$ & $=0,000088$ Areia $+0,000449$ Silte $+0,000448$ Argila $-0,058166 \mathrm{Ds}$ & $0,962 * *$ & 0,0372 \\
\hline$\hat{U}_{-1.500 \mathrm{kPa}}$ & $=0,000072$ Areia $+0,000195$ Silte $+0,000363$ Argila $-0,052198 \mathrm{Ds}$ & $0,957 * *$ & 0,0257 \\
\hline$\hat{U}_{33-1.500 \mathrm{kPa}}$ & $=0,000011$ Areia $+0,000261$ Silte $+0,000073$ Argila & $0,875^{* *}$ & 0,0245 \\
\hline \multicolumn{4}{|c|}{ Separação por grau aproximado de desenvol vimento } \\
\hline & Solos pouco desenvolvidos & & \\
\hline$\hat{U}_{-33 \mathrm{kPa}}$ & $=-0,000019$ Areia $+0,000106$ Silte $+0,000594$ Argila & $0,987 * *$ & 0,0154 \\
\hline$\hat{U}_{-1.500 \mathrm{kPa}}$ & $=-0,000007$ Areia $+0,000042$ Silte $+0,000293$ Argila & $0,979 * *$ & 0,0077 \\
\hline$\hat{U}_{33-1.500 \mathrm{kPa}}$ & $\begin{aligned}=-0,000060 \text { Areia }+0,000254 \text { Silte }-0,000104 \text { Argila }+0,046429 \mathrm{Ds} \\
\\
\text { Solos parcialmente desenvolvidos }\end{aligned}$ & $0,948 * *$ & 0,0159 \\
\hline$\hat{U}_{-33 \mathrm{kPa}}$ & $=-0,000073 \mathrm{Areia}+0,000259 \mathrm{Silte}+0,000280 \mathrm{Argila}+0,050707 \mathrm{Ds}$ & $0,942 * *$ & 0,0464 \\
\hline$\hat{U}-1.500 \mathrm{kPa}$ & $=0,000121$ Silte $+0,000260$ Argila & $0,946 * *$ & 0,0254 \\
\hline$\hat{\mathrm{U}}_{33-1.500 \mathrm{kPa}}$ & $\begin{aligned}= & -0,000027 \text { Areia }+0,000113 \text { Silte }+0,000028 \text { Argila }+0,041432 \mathrm{Ds} \\
& \text { Solos desenvolvidos a muito desenvolvidos }\end{aligned}$ & $0,935^{* *}$ & 0,0224 \\
\hline$\hat{U}_{-33 \mathrm{kPa}}$ & $=0,000108$ Areia $+0,000513$ Silte $+0,000469 \mathrm{Argila}-0,072730 \mathrm{Ds}$ & $0,967 * *$ & 0,0366 \\
\hline$\hat{U}-1.500 \mathrm{kPa}$ & $=0,000085$ Areia $+0,000229$ Silte $+0,000381$ Argila $-0,062662 \mathrm{Ds}$ & $0,965^{* *}$ & 0,0252 \\
\hline$\hat{U}_{33-1.500 \mathrm{kPa}}$ & $=0,000007$ Areia $+0,000262$ Silte $+0,000078$ Argila & $0,877^{* *}$ & 0,0253 \\
\hline
\end{tabular}

(1) Conteúdo estimado de água retida pelo solo no potencial especificado $\left(\mathrm{kg} \mathrm{kg}^{-1}\right){ }^{(2)}$ Os valores de areia, silte e argila em g kg ${ }^{-1}$ e os de densidade do solo em $\mathrm{t} \mathrm{m}^{-3}$. (3) Valores significativos a $1 \%$. 
pedofunções quanto à reunião dos dados num conjunto único, visto que os pequenos aumentos que foram constatados para alguns coeficientes de determinação foram, quase sempre, acompanhados por um aumento do erro-padrão da estimativa.

Esta tendência divergiu da obtida por Salchow et al (1996) e Pachepsky \& Rawls (1999), que obtiveram mel horias consideráveis após agruparem os sol os em categorias mais uniformes. Estes autores utilizaram, dentre outros critérios, a classe textural na categorização de seus dados.

Esperava-se uma melhoria na exatidão da estimativa após a categorização dos dados, uma vez quetal procedimento deveria reunir no mesmo grupo solos com similares relações de retenção de umidade e, por haver uma redução no número de amostras por grupo (Pachepsky \& Rawls, 1999). A separação por grau aproximado de desenvolvimento mostrouse eficienteapenas para o caso dos sol os considerados pouco evoluídos, em que o aumento de $R^{2}$ foi acompanhado pela diminuição do EPE. Como o número de casos de amostras de textura arenosa e siltosa foi muito pequeno, não foram elaboradas equações para estas classes texturais.

A figura 1 mostra o resultado da validação das equações elaboradas. Uma pequena tendência de superestimativa foi observada para água disponível. As correlações indicam que as equações são mais precisas na predição da umidade retida nos potenciais de -33 e $-1.500 \mathrm{kPa}$ do que da água disponível entre estes potenciais. As melhores correlações foram obti das para predição da umi dade a -1.500 kPa er eforçam a discussão de que a relação entre a retenção de umidade e a textura dos solos, ao menos até certo ponto, estreita-se à medida que aumenta a tensão, como foi discutido por Prevedelo (1996).

\section{Avaliação de equações similares}

O quadro 6 eas figuras 2 e 3 mostram oresultado das performances das equações selecionadas. As equações sel ecionadas para comparação demonstram uma baixa capacidade preditiva, traduzida pelos el evados valores para MRQEE eMREE, quetendem a super ou subestimação. Os val ores negativos para MREE indicam que os resultados estimados foram
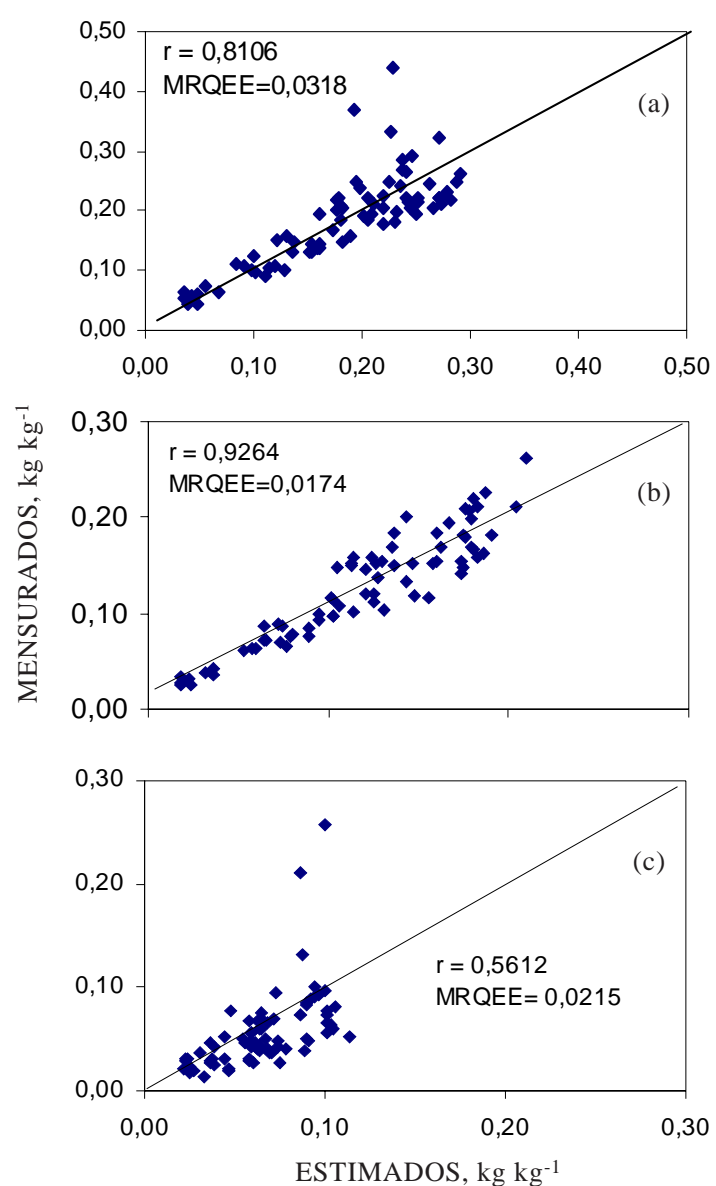

Figura 1. Comparação entre dados estimados e mensurados da validação das equações. a, b e c correspondem, respectivamente, à umidade a -33kPa, -1.500 kPa e água disponível.

Quadro 6. Avaliação de equações de regressão apresentadas na literatura baseada na raiz do quadrado da média do erro da estimativa (RMQEE)

\begin{tabular}{|c|c|c|c|c|}
\hline Autor & Umidade & E quação(1) & MRQEE & MREE \\
\hline Arruda et al. (1987) & $\begin{array}{l}\hat{U}_{-33 \mathrm{kPa}} \\
\hat{U}_{-1.500 \mathrm{kPa}} \\
\hat{U}_{33-1.500 \mathrm{kPa}}\end{array}$ & $\begin{array}{l}=\left(3,1+0,629(\text { Silte }+ \text { Argila }) / 10-0,0034((\text { Silte }+ \text { Argila }) / 10)^{2}\right) / 100 \\
=398,9((\text { Silte }+ \text { Argila }) / 10) /(1308,1+(\text { Silte }+ \text { Argila }) / 10) \\
\text { calculada pela diferença }\end{array}$ & $\begin{array}{l}0,0784 \\
0,0422 \\
0,0469\end{array}$ & $\begin{array}{l}-37,55 \\
-27,30 \\
-53,26\end{array}$ \\
\hline Meng et al. (1987) & $\begin{array}{l}\hat{U}_{-33 \mathrm{kPa}} \\
\hat{U}_{-1.500 \mathrm{kPa}}\end{array}$ & $\begin{array}{l}=-0,0044+0,0082 \text { Argila } / 10 \\
=-0,0028+0,0038 \text { Argila } / 10\end{array}$ & $\begin{array}{l}0,0980 \\
0,1361\end{array}$ & $\begin{array}{l}-55,19 \\
-13,69\end{array}$ \\
\hline Bell \& van Keulen (1995) & $\begin{array}{l}\hat{U}_{-1.500 \mathrm{kPa}} \\
\hat{U}_{-1.500 \mathrm{kPa}}\end{array}$ & $\begin{array}{l}=(6,93+0,286 \text { Argila/10)/100 (E quação 1) } \\
=(5,72+0,433 \text { Argila/10)/100 (E quação 2) }\end{array}$ & $\begin{array}{l}0,0631 \\
0,0966\end{array}$ & $\begin{array}{l}-55,46 \\
-88,66\end{array}$ \\
\hline Masutti (1997) & $\begin{array}{l}\hat{U}_{-33 \mathrm{kPa}} \\
\hat{U}_{33-1.500 \mathrm{kPa}}\end{array}$ & $\begin{array}{l}=(-1,5691+0,4289(\text { Argila }+ \text { Silte }) / 10) / 100 \\
=(-0,530482+0,301235 \text { Silte } / 10+0,092822 \text { Argila/10)/100 }\end{array}$ & $\begin{array}{l}0,0404 \\
0,0260\end{array}$ & $\begin{array}{l}-4,73 \\
-4,61\end{array}$ \\
\hline
\end{tabular}

(1) $\mathrm{O}$ valores de silte e argila em $\mathrm{g} \mathrm{kg}^{-1}$. 
superiores aos mensurados, ou seja, foram superestimados. As mel hores performances foram obtidas pelo emprego das equações propostas por
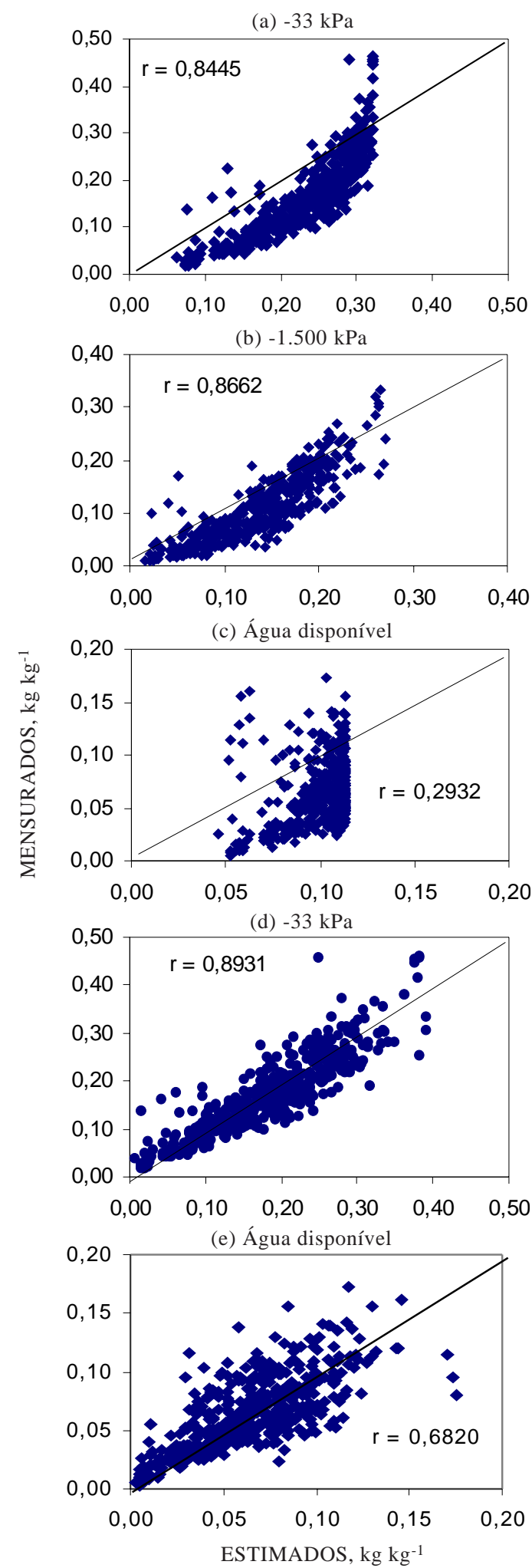

Figura 2. Comparação entre dados mensurados e estimados pelas equações propostas por Arruda et al. (1987) $(a, b, c)$ e Masutti $(1997)(d, e)$.
Masutti (1997), e o fato de ter o autor trabalhado com solos da Zona da Mata pernambucana é, possivelmente, a melhor explicação.

Todas as equações produziram valores superestimados de conteúdo de água retido nos potenciais especificados, com destaque para as equações propostas por Bell \& van Keulen (1995). Isto parece reforçar a idéia de que a utilização de pedofunções deve basear-se em calibrações locais, como destacado por Coelho et al. (1998).

(a) Equação 1

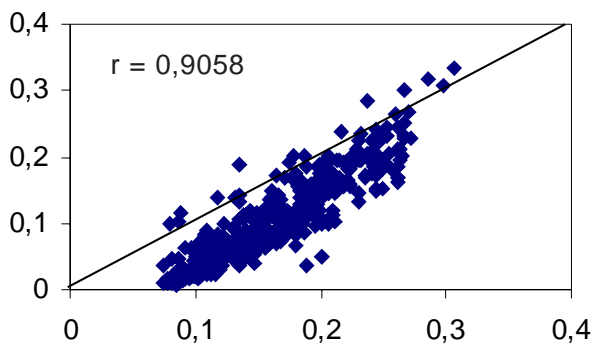

(b) Equação 2

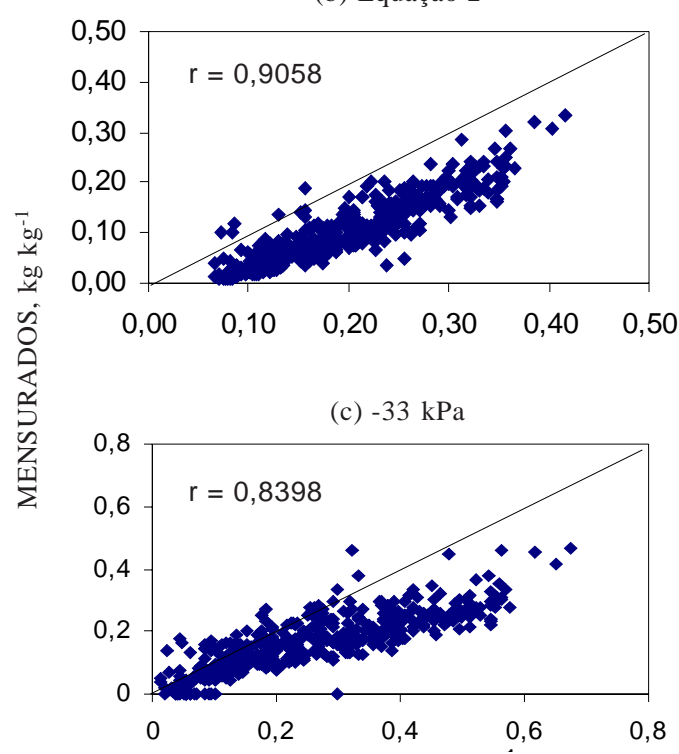

(d) $-1.500 \mathrm{kPa}$

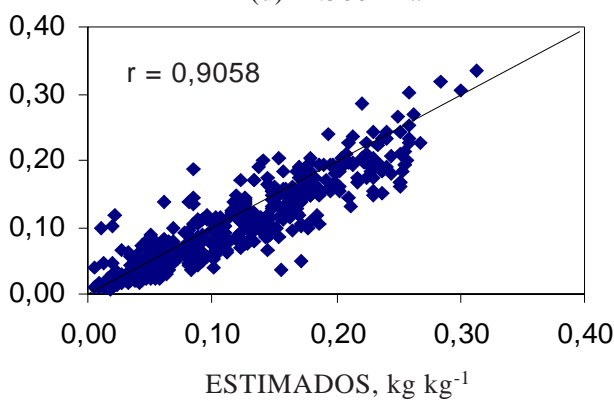

Figura 3. Comparação entre dados mensurados e estimados pelas equações propostas por Bell \& van Keulen (1995) para umidade retida a $-1.500 \mathrm{kPa}(\mathrm{a}, \mathrm{b})$ e por Meng et al. (1987) (c, d). 


\section{CONCLUSÕES}

1. O conteúdo de água retido nos potenciais de -33 e -1.500 kPa e a água disponível em solos do estado de Pernambuco podem ser estimados, com razoável precisão, a partir de dados granulométricos e de densidade do solo.

2. A categorização dos dados de acordo com a atividade da fração argila ou grau aproximado de desenvolvimento pedogenético ou dassetextural não produziu melhorias consideráveis na capacidade preditiva das pedofunções.

3. As equações avaliadas (de outros trabalhos) demonstraram baixa capacidade preditiva, quando aplicadas a solos do estado de Pernambuco.

\section{LITE RATURA CITADA}

AHUJ A, L.R.; NANEY, J.W. \& WI LLIAMS, R.D. Estimating soil water characteristics from simpler properties on limited data. Soil Sci. Soc. Am. J., 49:1100-1105, 1985.

ALVES, A.J .O. Caracterização e potencialidade dos solos da estação experimental de cana-de-açúcar deCarpina. Recife, Universidade Federal Rural de Pernambuco, 1994. (Tese de Mestrado)

ARRUDA, F.B.; ZULLO J r., J . \& OLIVEIRA, J.B. Parâmetros de solo para o cálculo da água disponível com base na textura do solo. R. Bras. Ci. Solo, 11:11-15, 1987.

BELL, M.A. \& van KEULEN, H. Soil pedotransfer frunctions for four mexican soils. Soil Sci. Soc. Am. J ., 59:865-871, 1995.

BERG, M.D.; KLANT, E.; van REEUWIJ K, L.P. \& SOMBROEK, W.G. Pedotransfer functions for the estimation of moisture retention characteristics of Ferrasols and related soils. Geoderma, 78:161-180, 1997.

COELHO, E.F.; CONCEIÇÃO, M.A.F. \& SOUZA, V.A.B. Estimativa dos limites de disponibilidade deágua em função da densidade gl obal e da textura do solo. R. Ceres, 45:183192, 1998.

COMPANHIA DE DESENVOLVIMENTO DO VALE DO SÃO FRANCISCO - CODEVASF. Projeto Sertão de Pernambuco: levantamento semi detal hado de sol os, classificação deterras para irrigação e aptidão agrícola das terras. Recife, 1998. $135 p$.

COSTA, E.F.S. Efeito do clima e do solo na produtividade da cana-de-açúcar (Saccharum spp) na Zona da Mata de Pernambuco. Recife, Universidade Federal Rural de Pernambuco, 1988. 224p. (Tese de Mestrado)

DANTAS, J.A. Averiguação dos efeitos da irrigação em solos podzólicos no sub-médio São Francisco. Recife, Universidade Federal Rural de Pernambuco, 1996. 104p. (Tese de Mestrado)
EMPRESA BRASILEIRA DE PESQUISA AGROPECUÁRIA EMBRAPA. Manual de métodos de análises de solos. Rio de J aneiro, 1979. 247p.

EMPRESA BRASILEIRA DE PESQUISA AGROPECUÁRIA EMBRAPA. Procedimentos normativos de levantamentos pedológicos. Brasília, 1995. 101p.

EMPRESA BRASILEIRA DE PESQUISA AGROPECUÁRIA EMBRAPA. Serviço de Produção de Informação - SPI. Sistema Brasileiro de Classificação de Solo. Brasília, 1999. $412 p$

GUSMÃO, G.O. E feito da cobertura morta sobre algumas características físicas e químicas do solo e sobre a produção de matéria seca da cultura do milho. Recife, Universidade Federal Rural de Pernambuco, 1993. 107p. (Tese de Mestrado)

KERN, J.S. Evaluation of soil water retention models based on basic soil physical properties. Soil Sci. Soc. Am. J ., 59:11341141, 1995.

LIER, Q.J . Índices da diponibilidade de água para as plantas. In: NOVAIS, R.F.;ALVAREZV., V.H.\& SHAEFER, C.E.G.R., eds. Tópicos em ciência do solo. Viçosa, SociedadeBrasileira de Ciência do Solo, 2000. p.95-106.

LIN, H.S. MCINNES, K.J .; WILDING, L.P. \& HALLMARK, C.T. Effects of soil morphology on hydraulic properties: II. Hydraulic pedotransfer functions. Soil Sci. Soc. Am. J., 63:955-961, 1999.

LUZ, L.R.Q.P. Pedogênese de uma topossequência de solos do semi-árido de Pernambuco. Recife, Universidade Federal Rural de Pernambuco, 1989. 96p. (Tese de Mestrado)

MASUTTI, M.M. Caracterização da água disponível a partir de parâmetros físico-hídricos em solos da zona da mata do estado de Pernambuco. Recife, Universidade Federal Rural de Pernambuco, 1997. 69p. (Tese de Mestrado)

MEDINA, B.F. \& OLIVEIRA J r., R.C. Relações entre capacidade de campo determinada in situ eem laboratório em latossolo amarelo muito argiloso. R. Bras. Ci. Solo, 11:91-95, 1987.

MENG, T.P.; TAYLOR, H.M.; FRYREAR, D.W. \& GOMEZ, J.F. Models to predict water retention in semiarid sandy soils. Soil Sci. Soc. Am. J., 51:1563-1565, 1987.

OLIVEIRA NETO, M.B. Pedogênese de uma topossequência no Agreste de Pernambuco. Recife, Universidade Federal Rural de Pernambuco, 1992. 142p. (Tese de Mestrado)

PACHEPSKY, A.Y. \& RAWLS, W.J . Acuracy and reability of pedotransfer functions as affected by grouping soils. Soil Sci. Soc. Am. J ., 63:1748-1757, 1999.

PARAHYBA, R.B.V. Gênse de solos planossólicos do Agreste de Pernambuco. Recife, Universidade Federal Rural de Pernambuco, 1993. 152p. (Tese de Mestrado)

PETERSEN, G.N.; CUNNINGHAM, R.L. \& MATELSKI, R.P. Moisture characteristics of Pennsylvania soils: I. Moisture retention as related to texture. Soil Sci. Soc. Am. Proc., 32:271-275, 1968.

PREVEDELLO, C.L. Física do solo: com problemas resolvidos. Curitiba, 1996. 446p. 
RAWLS, W.J .; GISA,T.J . \& BRAKENSIER, D.L. Estimating soil water retention from soil physical properties and characteristics. Adv. Soil Sci., 16:213-234, 1991.

RIBEIRO, M.R. Land suitability for sugarcane production in the coastal humid zone of Pernambuco state, Brazil. Saskatoon, University of Saskatchewan, 1982. 132p. (Tese de Doutorado)

REICHARDT, K. Capacidade de campo. R. Bras. Ci. Solo, 12:211-216, 1988.

SALCHOW, W.; LAL, R.; FAUSEY, N.R. \& WARD, A. Pedotransfer functions for variable alluvial soils in southern Ohio. Geoderma, 73:165-181, 1996.

SALTER, P.J . \& WILLIAMS, J.B. The influence of texture on the moisture characteristics of soils. II. Available water capacity and moisture release characteristics. J. Soil. Sci. 16:310-317, 1965.
SALTER, P.J .; BERRY, G. \& WILLIAMS, J.B. The influence of texture on the moisture characteristics of soils. III. Quantitative relationships between particle, composition, and available capacity. J. Soil. Sci. 17:93-98, 1966.

SAXTON,K.E.; RAWLS,W.J .; ROMBERGER,J.S. \& PAPENDICK, R.I. Estimating generalized soil-water characteristics form texture. Soil Sci. Soc. Am. J., 50:1031-1036, 1986.

SOUTO MAIOR, F.C. Podzólicos plínticos e os efeitos do cultivo de uva com irrigação no sub-médio São Francisco. Recife, Universidade Federal Rural de Pernambuco, 1996. 107p. (Tese de Mestrado)

SYSTAT, Inc. SYSTAT 5.03 for Windows. Evanston, 1993.

VEREECKEN, H.; MAES, J.; FEYEN, J.\& DARIUS, P. Estimating the soil moisture retention from characteristic texture, bulk density and carbon content. Soil Sci., 148:389403, 1989. 
L.B. OLIVEIRA et al.

R. Bras. Ci. Solo, 26:315-323, 2002 